\title{
Prevalence of epilepsy in a case series of multiple sclerosis patients
}

\author{
Cynthia Dumas Viveiros ${ }^{1}$, Regina Maria Papais Alvarenga ${ }^{2}$
}

\begin{abstract}
Objective: The prevalence of epilepsy in multiple sclerosis (MS) patients has been a subject of interest for some years. The objectives of this study were to describe the clinical, radiological and electroencephalographic characteristics of epileptic seizures and to calculate the prevalence of epilepsy in a case series of MS patients. Method: Medical charts of MS patients were reviewed and patients who had suffered epileptic seizures were identified. Results: Of 160 cases analyzed, 5 had suffered epileptic seizures and one had comorbid mesial hippocampal sclerosis, confirmed by magnetic resonance imaging in a patient with complex partial seizures that began fifteen years prior to her diagnosis of MS. In the other four patients, seizures occurred both during the acute phase of the disease and in the chronic phase. Conclusion: The prevalence of epileptic seizures in MS patients in this study was $2.5 \%$, similar to that found in other studies.
\end{abstract}

Key words: multiple sclerosis, epilepsy, prevalence, epileptic seizure.

\section{Prevalência de epilepsia numa coorte de pacientes com esclerose múltipla}

\section{RESUMO}

Objetivo: A prevalência da epilepsia em pacientes com esclerose múltipla (EM) tem sido objeto de interesse há vários anos. Os objetivos deste estudo foram descrever as características clínicas, radiológicas e eletroencefalográficas das crises epilépticas e estimar a prevalência de epilepsia na EM numa série de casos. Método: Foram revisados prontuários de pacientes com EM e identificados os casos que apresentaram crise epiléptica. Resultados: Dos 160 casos analisados, cinco apresentaram crise epiléptica, sendo que, um caso, houve a presença de comorbidade com esclerose mesial do hipocampo, comprovada através de ressonância magnética numa paciente com crises parciais complexas iniciadas quinze anos antes do diagnóstico de EM. Nos outros quatro pacientes, as crises ocorreram tanto na fase aguda da doença, como na fase crônica. Conclusão: A prevalência de crises epiléticas nos pacientes com EM neste estudo foi de $2,5 \%$, semelhante à encontrada em outros estudos.

Palavras-chave: esclerose múltipla, epilepsia, prevalência, crise epiléptica.

\section{Correspondence}

Regina Maria Papais Alvarenga

Hospital Universitário

Gaffrée e Guinle (HUGG)

Rua Mariz e Barros 775

20270-004 Rio de Janeiro RJ - Brasil

E-mail: regina_alvarenga@hotmail.com

Received 4 November 2009

Received in final form 20 March 2010

Accepted 29 March 2010
Multiple sclerosis (MS) is a chronic neurological disease that is clinically manifested by a wide spectrum of signs and symptoms that have been organized by Kurtzke ${ }^{1}$ in a dysfunction scale that analyzes seven functional systems distributed into pyramidal, sensory, cerebellar, brainstem, visual, bowel and bladder and cerebral functions. An eighth item on this scale is reserved for other, less common neuro- logical manifestations that may be related to the disease, such as epileptic seizures observed during the chronic phase of the disease or, less frequently, as an initial manifestation of the attack.

The prevalence of epilepsy in MS patients has been the focus of study since the beginning of this century; however, the topic remains controversial, since findings have varied from 0.89 to $17 \%$ according to 
the series studied ${ }^{2-4}$. There is evidence that patients with MS are at a greater risk of developing epileptic seizures compared to the general population $(0.5-1 \%)^{2,4}$.

No studies have yet been carried out on the association between epilepsy and MS in Brazilian patients. Until the 1970s, MS was considered to be very rare, almost nonexistent, in tropical regions of South America where the climate is hot and the population is ethnically diverse. Although epidemiological studies initiated in Brazil in the 1990s confirmed the low prevalence rates of MS (15\% in São Paulo and 5\% in Rio de Janeiro), they described the clinical profile and course of MS as being similar to the characteristics of the disease found in Caucasian populations in the northern hemisphere where prevalence rates are highest ${ }^{5,6}$. The objective of this present study was to analyze the frequency and characteristics of epileptic seizures in a cohort of ambulatory patients with MS in the city of Rio de Janeiro (Brazil), correlating clinical data with electroencephalography and neuroimaging findings.

\section{METHOD}

A descriptive, cross sectional study was carried out. The research project was approved by the accredited ethics committee of the University Hospital and Gafrèe Guinle.

Patients with MS diagnosed according to the criteria defined by McDonald et al. ${ }^{7}$ and revised by Polman et al. ${ }^{8}$, with epileptic crises as defined by the International League against Epilepsy (ILAE) ${ }^{9}$, were selected from SIAPEM $^{10}$, an electronic database for the evaluation of multiple sclerosis in tropical countries. The database search included all MS patients followed-up between 1997 and 2007 at the private clinic of one of the investigators (RMPA), a specialist in demyelinating diseases in the city of Rio de Janeiro, Brazil. Demographic and clinical data on MS patients were collected: sex, skin color, place of birth, age at first attack, number of attacks, clinical course of the disease in accordance with the consensus on its subtypes drawn up by Lublin and Reingold ${ }^{11}$ : relapsing remitting, secondary progressive, primary progressive or progressive relapsing, duration of the disease at the time of last visit, degree of disability at the last evaluation, analyzed according to the expanded disability status scale (EDSS) $)^{1}$, classification of MS as benign based on an EDSS score of 0-3 over a duration of 10 years of the disease ${ }^{12}$ and data on epileptic seizures occurring under the following circumstances: prior to the diagnosis of MS, as the only manifestation of the attack or occurring in the chronic phase of the disease. Patients with MS and epilepsy were contacted by one of the investigators (CDV), a specialist in neurophysiology certified by the Brazilian Society of Clinical Neurophysiology, and were invited to participate in the study. After signing the informed con- sent form, patients were submitted to the research protocol, which included the history of epileptic seizures, review of supplementary tests (electroencephalography [EEG] and magnetic resonance imaging [MRI]), an additional EEG using a 20-channel Nihon Kohden scanner and analyzed by the investigator (CDV), and an additional brain MRI using a 3-T scanner.

\section{RESULTS}

Data on 160 MS patients from the SIAPEM ${ }^{10}$ database were reviewed. One hundred and twenty of these patients (75\%) were female and 40 (25\%) male. Fifteen (9.3\%) were of mixed race and 145 (89.7\%) were white. Age at onset

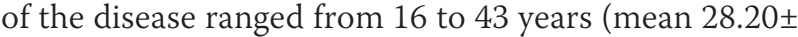
9.62 years).

With respect to the clinical course of MS, 133 patients initially had the relapsing-remitting form, of which 27 went on to develop the secondary progressive form of the disease. The remaining 10 patients had the primary progressive form, of which 5 had progressive relapsing MS. The neurological evaluation carried out at the last medical consultation after a median of 10 years of the disease (range 1-42 years) showed a median EDSS score of 3 (range $0-8$ ). Of the 94 patients who had had the disease for 10 years or more, 43 had an EDSS score $\leq 3$ corresponding to the benign form of the disease as defined by Weinshenker ${ }^{13}$. Familial MS was reported by two patients (a sister and a second-degree cousin), neither of whom had a family history of epilepsy.

Epileptic seizures occurred in five patients, four females and one male, all of whom were white. In the four women, the disease developed with a relapsing-remitting course, in a benign form, as defined by a mean duration of the disease of 16 years and an incapacity index rated between 0 and 2 . The only male patient had the primary progressive form of the disease, evolving with severe incapacity over the long term with the patient confined to a wheelchair at the last consultation, 30 years after onset of the disease.

\section{Clinical-laboratorial correlations}

The frequency and temporal relationship of the epileptic seizures with the clinical course of MS and electrographic findings from the intercritical period are shown in Table. EEG findings showed diffuse epileptiform abnormalities (Case 1) or abnormalities located unilaterally or bilaterally in the temporal regions (Cases 2 and 4), diffuse slowing or slowing localized in the temporal regions (Cases 1, 3 and 4), and normal tracing (Case 1).

Serial brain MRI scans were reviewed and all five patients who had had epileptic seizures were found to fulfill the MS radiological criteria defined by Barkhof ${ }^{11}$ and Tintoré $^{14}$. 
Table. Frequency and temporal relationship of the epileptic seizures with the clinical course of MS and electrographic findings.

\begin{tabular}{lll}
\hline & $\begin{array}{l}\text { Frequency and temporal relationship of the } \\
\text { epileptic seizures with the clinical course of MS }\end{array}$ & $\begin{array}{l}\text { Electrographic findings in the interictal } \\
\text { period of the time of the study }\end{array}$ \\
\hline Case 1 & Two epileptic seizures as clinical manifestations of MS & Previously \\
Female & attacks, the first and the third attacks. & - Groups of diffuse acute waves; Normal. \\
& & Currently \\
& - Groups of diffuse theta waves, predominantly in the bilateral \\
& frontal-temporal regions.
\end{tabular}

Case $2 \quad$ Numerous seizures beginning 10 years after the onset

Female of MS, occurring for two years until introduction of therapeutic doses of AEDs.

Case 3 Single seizure after 10 years of MS.

Female

Case 4

Female

Numerous epileptic seizures beginning after 15 years of age; the first MS attack began at 32 years of age.
Previously

- Groups of acute waves in the temporal regions, predominantly on the left.

- Normal

- Rare acute waves, isolated or in groups, in the frontal-temporal regions, with a slight tendency to be more pronounced to the left. Currently

- Rare groups of waves at the theta frequency and acute waves, in the bilateral temporal regions.

Currently

- Groups of slow waves localized in the bilateral temporal regions.

Previously

- Slowing in the temporal regions.

- Acute waves in the left temporal region.

- Normal.

Currently

- Rare acute waves localized in the temporal regions.

Case 5 Single seizure five years prior to the first MS attack. Not available

\section{Description of the seizures and MRI correlation}

Case 1 - A 30-year old woman had a complex partial seizure, motor symptoms on her right side, followed by secondary generalization. Investigation by her clinician included a brain computed tomography scan and cerebrospinal fluid evaluation for neurocysticercosis, which was unconfirmed. Four years later she developed paresthesia in her lower limbs, abdomen and hands, and Lhermitte's sign, together with small demyelinating cervical spine lesions. Complete remission was achieved with corticoid therapy. Three years later, she had a further complex partial seizure. Brain magnetic resonance imaging (MRI) showed a rounded area that was T1-hypointense and T2-hyperintense with perilesional edema, in addition to hyperintense lesions on T2 and FLAIR, localized in the periventricular and subcortical regions of both hemispheres of the brain, left middle cerebellar peduncle and right semioval center, with contrast uptake. Cervical spine MRI showed a hypersignal on T2 at an intramedullary site at C3. Treatment was initiated with interferon beta$1 \mathrm{a}$ and anticonvulsants. At the latest evaluation, the patient remains asymptomatic and MRI showed foci of de- myelination with no contrast uptake in the semioval centers, corona radiata and white matter adjacent to the lateral and subcortical ventricles of the frontal-parietal-occipital lobes.

Case 2 - A 45-year old woman had reversible, unilateral optic neuritis at 29 years of age. One year later the diagnosis of MS was confirmed following complaints of cervical spine pain and paresthesias in upper limbs. MRI showed a hypersignal on T2-weighted images of the posterolateral aspect of the cervical spine at $\mathrm{C} 2$ level, in addition to other similar images in the left middle cerebellar peduncle, tegmentum, periventricular white matter, and in the area perpendicular to the corpus callosum. In the ensuing years, she suffered further partially reversible seizures, characterized by central facial palsy and right hemiparesis coinciding with the appearance of new brain MRI lesions. At 37 years of age, she began to have tonicclonic convulsive seizures that were preceded by simple and complex partial seizures that were difficult to manage but eventually controlled with the use of anticonvulsant polytherapy. At the latest evaluation, the patient had pyramidal syndrome in all four limbs and left crural monopa- 
resis. MRI showed a hyperintense signal in the hippocampi and white matter in the temporal lobes as well as multiple hyperintense areas on T2 and FLAIR images, in the corpus callosum, callosal-septal interface, periventricular white matter, semioval center and corona radiata; with no contrast uptake. Foci were found in the brainstem, cerebellar peduncles and cerebellar hemispheres.

Case 3 - A 27-year old woman who, in the postpartum, presented medullary syndrome at T10 level, improving spontaneously after a few days. Six years later, six months after the birth of her second child, she had another thoracic attack at the same level, remission once again occurring spontaneously. Cervical and thoracic MRI showed non-contrast enhancing, hyperintense foci on T2 in the anterior portion of the bulbus and cervical spine at $\mathrm{C} 2$, as well as in the lateral portion of the thoracic spine at T4-T5. Some months later, optic neuritis developed on the left side. Brain MRI showed foci of hyperintense signal in the periventricular white matter on T2, frontal lobe, periventricular region, with contrast uptake. Other attacks occurred in the following years, characterized by numbness on one side of the face and tongue, tetraparesis and ophthalmoplegia of cranial nerve III. Fifteen years after the onset of the attacks, the patient had a complex partial seizure that began with motor manifestations in her right upper limb. Brain MRI showed a voluminous pseudotumoral lesion on the left temporal lobe on T1-weighted image, with annular contrast enhancement and multiple periventricular hyperintense foci with no contrast enhancement. Her most recent neurological evaluation was normal and MRI showed hyperintense lesions, situated bilaterally in the semioval center, corona radiata, in the white matter adjacent to the lateral ventricles, corpus callosum, callosal-septal interface, cerebellar hemispheres, left middle cerebellar peduncle and right cerebral peduncle. Reduction in the rounded lesion located in the left temporal lobe. Hippocampi slightly reduced in volume.

Case 4 - A 14-year old girl with recurrent complex partial seizures attributed to emotional problems. At 23 years of age, she began to have seizures again, with secondary generalization. She was treated with anticonvulsants, which controlled the seizures. At 45 years of age, she complained of diplopia and imbalance; however, a full recovery was reached following corticoid therapy. Eight months later, she had another seizure with the same characteristics as the previous ones. Brain MRI was compatible with mesial hippocampal sclerosis. Current neurological exam was normal and MRI showed multiple hyperintense, non-contrast enhancing foci in the white matter of the cerebral hemispheres, periventricular regions, cortical-subcortical regions of the insular, frontal and parietal lobes on the right, and callosal-septal interface.
Case 5 - A 27-year old male had a generalized tonic-clonic seizure. Eight years later, he developed paraparesis with slow progressive deterioration, eventually requiring a wheelchair. Brain MRI showed areas that were T2-hyperintense and T1-hypointense in the periventricular and subinsular white matter, and in the white matter present in the semioval centers, internal capsules and brainstem. It was not possible to carry out a current clinical and radiological evaluation in this case.

\section{DISCUSSION}

In 1994, Charles M. Poser ${ }^{15}$ already alerted the medical community to the need for greater accuracy in the diagnosis of MS for clinical research purposes, emphasizing the need for a differential diagnosis, established through clinical evaluation and supplementary testing, with other idiopathic, demyelinating diseases, particularly acute disseminated encephalomyelitis and optic neuritis. This investigator affirmed that the correct diagnosis of MS is the most important pillar of epidemiological studies.

Clinically, the diagnosis of MS requires at least two attacks to have occurred, indicating that different sites of the CNS have been affected at different times, i.e. dissemination in time and space. The course of the disease varies individually; however, the natural history of the relapsingremitting and primary progressive evolutive forms has already been defined. The relapsing-remitting form has the best prognosis but may, however, evolve to the secondary progressive form. In the present series, among the MS patients in whom onset of the disease occurred in the relapsing-remitting form, $57 \%$ of those in whom the duration of the disease was $\geq 10$ years had the benign form. This characteristic of MS in Brazilian patients has already been reported in other studies ${ }^{16,17}$. The primary progressive form occurs in $10-20 \%$ of cases and is differentiated from the other form by affecting both men and women similarly, by having a later onset and by leading to greater incapacity ${ }^{6}$. Confirming these data, the frequency of the primary progressive form of the disease in this sample population was $16 \%$ and only 1 of the 27 patients had mild incapacity after 10 years of the disease. The frequency of $2.9 \%$ of familial cases was similar to that found by Pereira ${ }^{18}$ among 640 MS patients enrolled at the Hospital da Lagoa in Rio de Janeiro, Brazil. As already defined, the functional systems most affected by MS consist of the pyramidal and sensory systems ${ }^{17}$. Epileptic seizures are very rare and their prevalence in the population of Rio de Janeiro remains to be defined.

Five patients of this series had epileptic seizures; however, only in four cases (three women and one man) was it possible to associate the epileptic seizure with the clinical status of MS. The disease progressed in the relapsingremitting form and was considered benign in the three 
female patients and primary progressive in the male patient, leading to severe incapacity over the mid-term.

The exact prevalence of epileptic seizures in MS patients is a controversial issue when analyzing serial studies. Epilepsy occurs in 0.5 to $1 \%$ of the general population. Studies on the relationship between epilepsy and MS have indicated a three to six-fold greater risk of an epileptic seizure in patients with MS compared to the general population ${ }^{3,19,20}$.

Methodological differences such as patient selection, differences in terminology, diagnostic criteria of MS, definition of epilepsy and a lack of differentiation between event-related seizures and seizures in epilepsy may be responsible for the difference in the prevalence rates reported in the various studies, which vary from $0.89 \%{ }^{21}$ to $17 \%^{4}$. According to Poser and Brinar ${ }^{22}$, criticism is justified when the diagnostic criteria for the selection of MS patients are not clear and standardized.

In the present study, if only the clinical data were taken into consideration, the prevalence of epileptic seizures and MS would be 3.1\%. However, analysis of serial studies of brain MRI and EEG enabled a causal relationship to be established between the diagnosis of mesial hippocampal sclerosis and partial control of the convulsive crises in one of the patients, leading to a lower prevalence of $2.5 \%$. This result was similar to those found in the studies carried out by Ghezzi et al. ${ }^{2}$ in Italy, Olafsson et al. ${ }^{19}$ in Iceland and Nicoletti et al. ${ }^{3}$ in Sicily, all of which included a greater number of cases.

In the MS patients of this study who had epileptic seizures, various aspects were identified with respect to the clinical data, the varying patterns of the seizures, the occurrence of seizures in the different evolutive phases of the disease and the electroencephalographic and neuroimaging results that are in accordance with data that have been described and discussed in the literature.

With respect to the pattern of the seizures, in the majority of cases the seizure was found to be of the partial type with or without secondary generalization, which is to be expected considering the relationship with the subcortical and juxtacortical inflammatory lesions as shown in the neuroimaging exams.

Chronic epilepsy is presumably unrelated to new attacks of MS but relates rather to the effect of the location of the disease on the cortical plate. According to Lebrun ${ }^{20}$, epileptic seizures may begin during the chronic phase of MS with no active inflammation and are generally associated with cerebral atrophy and an elevated number of lesions. Case 2, the only patient with recurrent seizures that began 10 years after the first MS attack, fits this model in which brain MRI shows no acute inflammatory activity but a large number of confluent lesions affecting the white brain matter, and cortical atrophy. Serial brain MRI scans, including the scan carried out on the 3-Tesla scanner, showed that the majority of lesions characterized by hyperintense signals were situated in the white matter of the temporal lobes, causing thinning of the hippocampus.

The susceptibility of the hippocampus, amygdala and temporal lobe in triggering epileptic seizures in central inflammatory diseases has been clearly demonstrated in this study. In addition to the patient described above, who had chronic epilepsy associated with lesions to the temporal lobes, the patient in Case 3 had a complex partial seizure with a single manifestation of an acute pseudotumoral MS lesion associated with intense inflammatory activity localized in the temporal lobe. The effect on the temporal lobe in the postcritical period and over the long-term also led to cognitive dysfunction.

In agreement with the data reported by Ghezzi ${ }^{2}$, no correlation was found between the frequency of epileptic seizures and the severity of MS analyzed using the incapacity index. Even in the patient with the relapsing-remitting form who had a large number of epileptic seizures over a period of one year until initiating continuous use of the appropriate anticonvulsant drug to control the crises, EDSS score was 3 after 29 years of the disease, thereby classifying this patient as having the benign form of MS.

At the time of their epileptic seizures, none of the patients in this study were in use of any drugs that could have triggered the seizures such as methylprednisolone or interferon, although they had used them at some time during their illness.

It is well-known that MS predominantly affects the deep and periventricular white matter; however, demyelinating lesions have also been detected in the juxtacortical region and even inside the cerebral cortex. Brownell and Hughes ${ }^{23}$ found a total of 1,594 plates in the histopathological exams of 22 patients, of which 80 (5\%) were in the cortex and 265 (17\%) were at the cortex-white matter junction. The accumulation of cortical and subcortical lesions has been shown to be greater in cases of MS with epilepsy compared to those cases without epilepsy.

Five out of 160 patients had epileptic seizures at some phase of the disease; however, it was only established that the seizure was related to MS in four of these cases, resulting in a prevalence of $2.5 \%$. This study reinforces the need for supplementary MRI investigation in epidemiological studies on MS, since this diagnostic tool is capable of identifying other types of CNS lesions related to the appearance of epileptic seizures, such as mesial hippocampal sclerosis, as shown in one of the cases of this series.

\section{REFERENCES}

1. Kurtzke JF. Rating neurologic impairment in multiple sclerosis: an Expanded Disability Status Scale (EDSS). Neurology 1983;33:1444-1452.

2. Ghezzi A, Montanini R, Basso PF, Zaffaroni M, Massimo E, Cazzullo CL. Epilepsy in multiple sclerosis. Eur Neurol 1990;30:218-223. 
3. Nicoletti A, Sofia V, Biondi R, et al. Epilepsy and multiple sclerosis in Sicily: a population-based study. Epilepsia 2003;44:1445-1448.

4. Ganguly G, Barma P, Das SK, Roy T. Seizures in multiple sclerosis in Eastern India. Neurology Asia 2006;11:123-127.

5. Papais-Alvarenga RM, Santos CMM, Abreu JS, et al. Esclerose múltipla: perfil clínico e evolutivo no municipio do Rio de Janeiro. Análise das manifestações neurológicas prevalentes em 291 surtos de 88 pacientes. Rev Bras Neurol 1995;31:75-87.

6. Vasconcelos CCF. Esclerose múltipla forma inicialmente progressiva: estudo clínico e evolutivo de 26 casos da cidade do Rio de Janeiro. Dissertação. Universidade Federal Fluminense, 2004

7. Mcdonald WI, Compston A, Edan G, et al. Recommended diagnostic criteria for multiple sclerosis: guidelines from the International Panel on the diagnosis of Multiple Sclerosis. Ann Neurol 2001;50:121-127.

8. Polman CH, Reingold SC, Edan G. Diagnostic criteria for multiple sclerosis: 2005 revisions to the "McDonald Criteria". Ann Neurol 2005;58:840-806.

9. Commission on Classification and Terminology of the International League Against Epilepsy. Proposal for revised classification of epilepsies and epileptic syndromes. Epilepsia 1989;30:389-399.

10. Papais Alvarenga RM, Alves Leon S, Tilbery CP, Poser C, Miranda Santos CM. SIAPEM - Brazilian Software Database for Multiple Sclerosis Research in Tropical Countries. African J Neurol Sci 2003;22:10-20.

11. Lublin F. Clinical features and diagnosis of multiple sclerosis. Neurol Clin 2005; 23:1-15.

12. Weinshenker B. The natural history of multiple sclerosis. Neurol Clin 1996; 13:119-146.

13. Barkhof F, Filippi M, Miller DH. Comparison of MRI criteria at first presenta- tion to predict conversion to clinically definite multiple sclerosis. Brain 1997; 12:2059-2069

14. Tintorè M, Rovira $\mathrm{A}$, Martiniez MJ. Isolated demyelinating syndrome: comparison of different MRI criteria to predict conversion to clinically definite multiple sclerosis. Am J Neuroradiol 2000;1:702-706.

15. Poser CM, Paty DW, Scheinberg LC, et al. New diagnostic criteria for multiple sclerosis: guidelines for research protocols. Ann Neurol 1983;13:227-231.

16. Moreira MA, Felipe E, Mendes Mf, Tilbery CP. Esclerose múltipla: estudo descritivo de suas formas clínicas em 302 casos. Arq Neuropsiquiatr 2000; 58:460-466.

17. Alvarenga RMP, Alves-Leon SV, Miranda-Santos CM. South Atlantic Project: a Brazilian multiple sclerosis trial. In: Arriagada CR, Nogales-Gaete J (Eds). Esclerosis multiple: una mirada ibero-panamericana. Santiago-Chile: Arrynogediciones, 2002:129-154

18. Pereira FFCC. Aspectos demográficos, clínicos e evolutivos da forma familiar de esclerose múltipla em pacientes brasileiros atendidos no hospital da lagoa/ centro de referência de doenças desmielinizantes. Dissertação. Universidade Federal do Estado do Rio de Janeiro, 2006

19. Olafsson E, Benedikz J, Hauser WA. Risk of epilepsy in patients with multiple sclerosis: a population-based study in Iceland. Epilepsia 1999:40: 745-747.

20. Lebrun C. Epilepsy and multiple sclerosis. Epileptic Disord 2006;8:555-558.

21. Nyquist PA, Cascino GD, Rodriguez M. Seizures in patients with multiple sclerosis seen at Mayo Clinic, Rochester, Minn, 1990-1998. Mayo Clin Proc 2001; 76:983-986.

22. Poser CM, Brinar W. Epilepsy and multiple sclerosis. Epilep Behav 2003;4:6-12

23. Brownell B, Hughes JT. The distribution of plaques in the cerebrum in multiple sclerosis. J Neurol Neurosurg Psychiatry 1962;25:315-320. 